\title{
Nearly 30 Years of Treatment for Recurrent Granulosa Cell Tumor of the Ovary: A Case Report and Review of the Literature
}

\author{
Deanna Teoh $^{\mathrm{a}}$ Ralph Freedman ${ }^{\mathrm{b}}$ Pamela T. Soliman ${ }^{\mathrm{b}}$ \\ aDepartment of Gynecologic Oncology, Duke University, Durham, N.C., and \\ ${ }^{b}$ Department of Gynecologic Oncology, University of Texas, M.D. Anderson \\ Cancer Center, Houston, Tex., USA
}

\section{Key Words}

Granulosa cell tumor $\cdot$ Hormonal therapy - Ovarian cancer - Chemotherapy

\begin{abstract}
A 30-year-old woman was diagnosed with a stage IA granulosa cell tumor (GCT) of the ovary in 1979. Following removal of the adnexal mass and complete surgical staging, she remained disease-free for 12 years. In 1991 she underwent a resection of a retroperitoneal mass, confirmed to be a recurrent GCT. Despite adjuvant radiation treatment at the time of recurrence, the patient presented five years later with abdominal pain, and was found to have a second recurrence. Over the next 10 years the patient had multiple recurrences and progressive disease despite surgical resection, cytotoxic, hormonal and targeted chemotherapy treatments. In conclusion, there is no standard management for recurrent GCT of the ovary. We review this patient's treatment in the context of the current literature.
\end{abstract}

\section{Case Report}

A 30-year-old female was diagnosed with a granulosa cell tumor (GCT) of the right ovary in 1979 at the time of a right oophorectomy for an adnexal mass. The patient was then referred to the University of Texas M.D. Anderson Cancer Center and underwent a total abdominal hysterectomy, left salpingoophorectomy and staging procedure which revealed no residual disease. No further treatment was recommended. The patient remained disease-free for 12 years; however, in April 1991 she was noted to have a retroperitoneal mass. A second exploration was performed with removal of the mass, right lymphadenectomy and multiple biopsies. The mass was consistent with recurrent GCT; however, the lymph nodes and biopsies were negative. The patient was treated with pelvic radiation for a total dose of 5,000 cGy in 25 fractions and was without evidence of disease until June 1996, when the patient 


\begin{tabular}{|c|c|c|c|}
\hline $\begin{array}{c}\text { Case Reports in } \\
\text { Ence.ail }\end{array}$ & $\begin{array}{l}\text { Case Rep Oncol 2010;3:14-18 } \\
\text { Dol: 10.1159/000274590 }\end{array}$ & Published online: January 13, 2010 & \begin{tabular}{|l} 
@ 2010 S. Karger AG, Basel \\
ISSN 1662-6575 \\
www.karger.com/cro
\end{tabular} \\
\hline
\end{tabular}

underwent a second resection of a right retroperitoneal mass with a segmental resection of the right hemi-diaphragm for recurrent disease. Follow-up imaging studies were negative for disease.

A year later, a recurrence of tumor was detected at the apex of the vagina and the patient was treated with leuprolide acetate $22.5 \mathrm{mg}$ subcutaneously every three months and tamoxifen $20 \mathrm{mg}$ orally twice daily. Several months later, however, progressive disease was noted and a fourth tumor-reductive surgery, lysis of adhesions, and small bowel resection with primary reanastomosis was performed. The patient again remained disease-free for four years until she developed a $14-\mathrm{cm}$ right-sided liver mass. After a consultation with gastrointestinal surgical oncology, the patient underwent a partial right liver resection with removal of the mass in March 2002.

One year later, recurrent tumor was noted in the right diaphragmatic area and the patient was treated with nine cycles of carboplatin and paclitaxel. She had a complete response to therapy; however, five months later, the patient was noted to have multiple peritoneal implants and lung nodules. The tumor was both estrogen (75\%) and progesterone receptor positive (90\%). She received megestrol acetate $40 \mathrm{mg}$ orally four times daily for three months and was noted to have progressive disease. The patient was then treated with multiple chemotherapy regimens including bleomycin, etoposide, cisplatin (BEP) for six cycles, oral etoposide for two cycles, liposomal doxorubicin for nine cycles, gemcitabine for four cycles, and weekly topotecan for three cycles. Due to progressive disease, in September 2006 the patient was started on bevacizumab $7 \mathrm{mg} / \mathrm{kg}$ every other week and after three cycles was noted to have progression of disease. The patient was offered enrollment into a phase I clinical trial, however, she declined further treatment.

\section{Chemotherapy}

Platinum- and taxane-based chemotherapy have become the standard adjuvant treatment for gynecologic cancers, and it is often the first regimen used for GCT after surgical resection. Although data regarding the efficacy of carboplatin and paclitaxel in the treatment of GCT is lacking, multiple small studies have demonstrated tumor response to platinum-based regimens.

Gershenson et al. [1] reported an overall response rate of $63 \%$ in 8 patients treated with cisplatin, doxorubicin, and cyclophosphamide, 38\% complete response (CR) and 25\% partial response (PR). Pectasides et al. [2] treated 10 patients, four with residual disease after primary diagnosis, and six with extensive disease at relapse. All of the patients treated after the primary diagnosis achieved a CR. In the six patients treated at the time of recurrence, one had a CR and one had a PR. Overall, toxicity was minimal.

The combination of cisplatin, vinblastine and bleomycin - which has been used to treat testicular sex cord-stromal tumors - has also been described in treatment of GCT. Colombo et al. [3] treated 11 patients with this regimen, six had CRs and three PRs. In a prospective study, an overall response rate of $66 \%$ was found in seven patients with advanced or recurrent GCT [4]. This regimen was eventually changed to BEP, due to data in testicular sex cord-stromal tumors showing a similar response rate with less toxicity.

In a prospective study at M.D. Anderson Cancer Center (MDACC) from 1988-1993, nine patient with sex cord-stromal tumors of the ovary were treated with first-line BEP. The overall response rate was $83 \%, 33 \%$ having a CR and $50 \%$ a PR. One of the five who initially responded to treatment (20\%) had a durable response [5]. In a larger prospective study by the Gynecologic Oncology Group [6], 57 patients with stage II-IV sex cordstromal tumors (48 with GCT) received first-line BEP. Of those, 55 had a CR and 37\% (14/38) had a negative second look. Sixty-nine percent of patients with advanced disease and $51 \%$ with recurrent disease remained disease-free at three years, thus making BEP an attractive first-line regimen for GCT. 


\begin{tabular}{c|l|l|l}
$\begin{array}{c}\text { Case Reports in } \\
\text { Pintriajy }\end{array}$ & $\begin{array}{l}\text { Case Rep Oncol 2010;3:14-18 } \\
\text { Dol: } 10.1159 / 000274590\end{array}$ & & $\begin{array}{l}\text { Published online: January 13, 2010 S. Karger AG, Basel } \\
\text { ISSN 1662-6575 } \\
\text { www.karger.com/cro }\end{array}$ \\
\hline
\end{tabular}

\section{Hormonal Treatment of GCT}

Hormonal therapy is another promising option for treatment of GCT. In a review of 22 GCT, all of the tumors were progesterone receptor positive, and 32\% were estrogen receptor positive [7].

Progestins such as megestrol acetate reduce estrogen secretion by inhibiting the production of pituitary gonadotropin. It also interferes with the availability, stability and turnover of estrogen and may interact with genes at the estrogen or progestin receptor complex. One proposed mechanism of its anti-tumor effect is that continuous progesterone causes downregulation of progesterone receptors.

Gonadotropin-releasing hormone (GnRH) analogs like leuprolide acetate inhibit gonadrotropin release through inhibition of ovarian steroidogenesis. This in turn may decrease stimulation of the granulosa cells. There have been several reported cases of response to GnRH analogs in recurrent GCT. Five patients with advanced ovarian GCT had stabilization of disease or decreased inhibin levels in the first three months of treatment with GnRH agonists [8]. A prospective study of leuprolide acetate therapy for six patients with recurrent or persistent GCT showed a $40 \%$ partial response rate, with stable disease in the remaining $60 \%$. The progression-free interval was 3-13 months [9]. In all three of these studies, treatment with GnRH analogs was well tolerated and there were no significant side effects reported.

Estrogen is also known to increase granulosa cell responsiveness to follicle stimulating hormone; therefore, estrogen suppression via hormonal manipulation may decrease cell proliferation in GCT. The use of aromatase inhibitors such as anastrozole in the treatment of refractory GCT has been recently reported. Two patients who had progressive disease despite multiple chemotherapy regimens as well as leuprolide acetate were found to respond to anastrozole for 14 and 18 months [10].

\section{Radiotherapy in GCT}

Reports of radiation therapy for treatment of GCT of the ovary are generally favorable, although studies tend to be small and evaluation of disease response is not uniform. Fourteen patients with GCT and clinically measurable disease were treated with pelvic radiation at MDACC. A CR was reported in six patients (43\%), three were without evidence of disease at 21 years follow-up, the other three patients recurred $4-5$ years after completion of radiation. The remaining eight patients had either no response or progressed during radiation treatment. Median survival was 12 months [11]. A 50\% CR rate with radiation treatment has also been reported in other studies [12].

Recently, Choan et al. [13] reported three cases of recurrent or residual GCT of the ovary treated with radiation, a dose of 30-50 gray. Tumor volume was reduced by $85-$ $90 \%$ in all three cases with duration of response of 5 to 21 months. Two of the three patients, however, developed recurrent disease within the abdomen but outside of the radiated field.

\section{Targeted Therapy and GCT}

Anti-angiogenic agents have been recently considered in treatment of multiple cancers including ovarian cancer. Metastasis through vascular spread is thought to be of 
particular importance with ovarian cancer because of the absence of lymphatic channels in the ovary. Bevacizumab is a human monoclonal antibody that binds to vascular endothelial growth factor (VEGF). It has been used for treatment of colon, lung and breast cancer and is currently under investigation as a treatment for ovarian cancer. VEGF regulates angiogenesis in epithelial ovarian cancer which has been associated with disease progression; thus, bevacizumab is an attractive agent for ovarian cancer and possibly GCT. While the current data in ovarian cancer is somewhat limited, the efficacy of bevacizumab has been shown in several studies $[14,15]$. Phase III trials of bevacizumab in heavily pre-treated ovarian cancer patients are currently underway.

\section{Conclusion}

GCT of the ovary are classified as stromal tumors and represent $2-5 \%$ of all ovarian cancers. In general, GCT are indolent tumors with late recurrence. Although this might be considered a favorable characteristic, their unpredictable behavior, particularly for the adult type, can complicate their management. This case report illustrates the characteristic behavior of a patient who developed multiple recurrences of GCT of the ovary. The literature is reviewed in the context of the treatment that this patient received. No standard adjuvant regimen has been defined to date, but there is data to support the use of platinum-based chemotherapy, as well as hormonal therapy. Radiation is also a therapeutic option for localized disease. The role of novel therapeutics will begin to unfold as further studies become available in both epithelial and stromal ovarian cancers. 


\begin{tabular}{c|l|l|l}
$\begin{array}{c}\text { Cose Reports in } \\
\text { Pinciajl }\end{array}$ & $\begin{array}{l}\text { Case Rep Oncol 2010;3:14-18 } \\
\text { Dol: } 10.1159 / 000274590\end{array}$ & & $\begin{array}{l}\text { Published online: January 13, 2010 S. Karger AG, Basel } \\
\text { ISS 1662-6575 } \\
\text { Www.karger.com/cro }\end{array}$ \\
\hline
\end{tabular}

\section{References}

1 Gershenson DM, Copeland LJ, Kavanagh JJ, Stringer CA, Saul PB, Wharton JT: Treatment of metastatic stromal tumors of the ovary with cisplatin, doxorubicin, and cyclophosphamide. Obstet Gynecol 1987;70:765-769.

$\checkmark 2$ Pectasides D, Alevizakos N, Athanassiou AE: Cisplatin-containing regimen in advanced or recurrent granulosa cell tumours of the ovary. Ann Oncol 1992;3:316-318.

3 Colombo N, Sessa C, Landoni F, Sartori E, Pecorelli S, Mangioni C: Cisplatin, vinblastine, and bleomycin combination chemotherapy in metastatic granulosa cell tumor of the ovary. Obstet Gynecol 1986;67:265-268.

4 Zambetti M, Escobedo A, Pilotti S, De Palo G: cisplatinum/vinblastine/bleomycin combination chemotherapy in advanced or recurrent granulosa cell tumors of the ovary. Gynecol Oncol 1990;36:317-320.

5 Gershenson DM, Morris M, Bruke TW, Levenback C, Matthews CM, Wharton JT: Treatment of poor-prognosis sex cord-stromal tumors of the ovary with the combination of bleomycin, etoposide, and cisplatin. Obstet Gynecol 1996;87:527531.

6 Homesley HD, Bundy BN, Hurteau JA, Roth LM: Bleomycin, etoposide, and cisplatin combination therapy of ovarian granulosa cell tumors and other stromal malignancies: A Gynecologic Oncology Group study. Gynecol Oncol 1999;72:131-137.

7 Hardy RD, Bell JG, Nicely CJ, Reid GC: Hormonal treatment of a recurrent granulosa cell tumor of the ovary: case report and review of the literature. Gynecol Oncol 2005;96:865-869.

-8 Kauppila A, Bangah M, Burger H, Martikainen H: GnRH agonist analog therapy in advanced/recurrent granulosa cell tumors: further evidence of a role of inhibin in monitoring response to treatment. Gynecol Endocrinol 1992;6:271-274.

-9 Fishman A, Kudelka AP, Tresukosol D, Edwards CL, Freedman RS, Kaplan AL, Girtanner RE, Kavanagh JJ: Leuprolide acetate for treating refractory or persistent ovarian granulosa cell tumor. J Reprod Med 1996;41:393-396.

10 Freeman SA, Modesitt SC: Anastrozole therapy in recurrent ovarian adult granulosa cell tumors: a report of 2 cases. Gynecol Oncol 2006;103:755-758.

$\checkmark 11$ Wolf JK, Mullen J, Eifel PJ, Burke TW, Levenback C, Gershenson DM: Radiation treatment of advanced or recurrent granulosa cell tumor of the ovary. Gynecol Oncol 1999;73:35-41.

12 Savage P, Constenla D, Fisher C, Shepherd JH, Barton DP, Blake P, Gore ME: Granulosa cell tumours of the ovary: demographics, survival and the management of advanced disease. Clin Oncol (R Coll Radiol) 1998;10:242-245.

13 Choan E, Samant R, Fung MFK, Le T, Hopkins L, Senterman M: Palliative radiotherapy for recurrent granulosa cell tumor of the ovary: a report of 3 cases with radiological evidence of response. Gynecol Oncol 2006;102:406-410.

14 Cannistra SA, Matulonis UA, Penson RT, Hambleton J, Dupont J, Mackey H, Douglas J, Burger RA, Armstrong D, Wenham R, McGuire W: Phase II study of bevacizumab in patients with platinum-resistant ovarian cancer or peritoneal serous cancer. J Clin Oncol 2007;25:5180-5186.

15 Burger RA, Sill MW, Monk BJ, Greer BE, Sorosky JI: Phase II trial of bevacizumab in persistent or recurrent epithelial ovarian cancer or primary peritoneal cancer: a Gynecologic Oncology Group Study. J Clin Oncol 2007;25:5165-5171. 